\title{
PENGARUH BUDAYA ORGANISASI KEPEMIMPINAN DAN LINGKUNGAN TERHADAP KEPUASAN KERJA KARYAWAN PADA UD SUWARLA NDONO ART DI TANGGULANGIN
}

\section{Ayu Faiza Rochmah, Bowo Santoso, Endang Iriyanti}

Universitas Pembangunan Nasional (UPN) Veteran, Jawa Timur, Indonesia

Email: ayufaizarochmah1@gmail.com, manajemen.boow@gmail.com, endang.ma@upnjatim.ac.id

\section{Abstract}

In terms of employees who work, job satisfaction is an important factor to note. An individual will feel satisfied at work if the aspects of the job and himself are supportive. Job satisfaction is formed from several aspects, including organizational culture, leadership, and work environment. On the basis of this thought, this study aims to determine the influence of Organizational Culture, Leadership, and Work Environment on Employee Job Satisfaction at UD. Suwarlandono Art at Tanggulangin. This study uses primary data obtained from respondents' answers with a sample of 60 employees in the production department. Data analysis techniques using Partial Least Square. The results of the study can be concluded that Organizational Culture, Leadership, and Work Environment have a positive and significant influence on Employee Job Satisfaction.

Keywords: organizational culture; leadership; work environment; and job satisfaction.

\begin{abstract}
Abstrak
Dari sisi karyawan yang bekerja kepuasan kerja merupakan faktor yang penting untuk diperhatikan. Seorang individu akan merasa puas dalam bekerja apabila aspekaspek dari segi pekerjaan dan dirinya mendukung. Kepuasan dalam kerja terbentuk dari beberapa aspek, diantaranya budaya organisasi, kepemimpinan, dan lingkungan kerja. Atas dasar pemikiran tersebut penelitian ini bertujuan untuk mengetahui pengaruh Budaya Organisasi, Kepemimpinan, dan Lingkungan Kerja terhadap Kepuasan Kerja Karyawan pada UD. Suwarlandono Art di Tanggulangin. Penelitian ini menggunakan data primer yang diperoleh dari jawaban responden dengan sampel sebanyak 60 orang karyawan di bagian produksi. Teknik analisis data menggunakan Partial Least Square. Hasil penelitian dapat disimpulkan bahwa Budaya Organisasi, Kepemimpinan, dan Lingkungan Kerja memiliki pengaruh positif dan signifikan terhadap Kepuasan Kerja Karyawan.
\end{abstract}

Kata Kunci: budaya organisasi; kepemimpinan; lingkungan kerja; dan kepuasan kerja

\begin{tabular}{ll}
\hline How to cite: & $\begin{array}{l}\text { Rochmah, Ayu.Faiza, Bowo Santoso,.Endang Iriyanti (2021) Pengaruh Budaya Organisasi } \\
\text { Kepemimpinan Dan Lingkungan Kerja Terhadap Kepuasan Kerja Karyawan Pada Ud. }\end{array}$ \\
& Suwarlandono Art Di Tanggulangin, (3)6. https://doi.org/10.36418/syntax-idea.v3i6.1225 \\
E-ISSN: & $2684-883 X$ \\
Published by: & Ridwan Institute
\end{tabular}




\section{Pendahuluan}

Dari sisi karyawan yang bekerja kepuasan kerja merupakan faktor yang penting untuk diperhatikan. Seorang individu akan merasa puas dalam bekerja apabila aspek aspek dari segi pekerjaan dan dirinya mendukung. Tetapi sebaliknya jika aspek-aspek dari segi pekerjaan maupun dari dirinya tidak mendukung maka individu tersebut akan merasa tidak puas. Menurut (Handoko, 2016) menyatakan kepuasan kerja merupakan keadaan emosional yang menyenangkan atau tidak menyenangkan para karyawan memandang pekerjaan mereka. Kepuasan kerja karyawan menjadi topik yang menarik untuk selalu dikaji karena sifatnya yang kompleks dan menghasilkan aneka ragam temuan dalam konteks berbagai bidang industri. Namun secara umum kepuasan kerja juga bisa dipengaruhi oleh budaya organisasi, kepemimpinan dan lingkungan kerja.

Budaya organisasi merupakan salah satu faktor yang dapat mempengaruhi kepuasan kerja karyawan. Di dalam perusahaan terdapat budaya organisasi yang melekat di suatu perusahaan yang dianut bersama oleh seluruh karyawan. Budaya organisasi merupakan sumber daya organisasi yang bersifat dinamis bertujuan untuk mencapai efisiensi dengan efektivitas di suatu perusahaan. Di dalam perusahaan, budaya organisasi sangat penting karena di dalam perusahaan terdapat perbedaan antar karyawan satu dengan karyawan lainnya, maka dari itu pemimpin ingin menyatukan perbedaan-perbedaan tersebut dengan membentuk budaya organisasi di perusahaan. Dengan adanya budaya organisasi di suatu perusahaan, akan berperan penting dalam memudahkan karyawan untuk menyesuaikan diri dengan lingkungan perusahaan, dan dapat juga membantu karyawan dalam hal mengetahui tindakan yang seharusnya dilakukan oleh karyawan sesuai dengan nilai-nilai yang menjadi pegangan bagi karyawan dalam menjalankan kewajiban dan perilakunya di perusahaan untuk mendapatkan hasil yang maksimal. Menurut (Robbins, S. y Judge, 2014a) menyatakan bahwa budaya organisasi adalah suatu sistem berbagai arti yang dilakukan oleh para anggota yang membedakan suatu organisasi dengan organisasi lainnya. Dengan adanya budaya organisasi yang kuat maka bisa mendukung tercapainya suatu tujuan organisasi yang akan mengarah terhadap kepuasan kerja karyawan.

Selain budaya organisasi yang selalu melekat dan dianut oleh setiap anggota organisasi. Kepemimpinan juga merupakan sumber kepuasan kerja seseorang. Kepemimpinan yang efektif dalam suatu perusahaan memiliki peran yang sangat penting untuk meningkatkan kemajuan perusahaan. Menurut (Potale \& Uhing, 2015) menyatakan kepemimpinan merupakan kemampuan individu dengan menggunakan kekuasaannya melakukan proses mempengaruhi, memotivasi, dan mendukung usaha yang memungkinkan orang lain memberikan kontribusi pada pencapaian tujuan organisasi. Keberhasilan ataupun kegagalan dari suatu organisasi ditentukan oleh kepemimpinan yang berjalan di organisasi tersebut. Pemimpin yang berhasil adalah pemimpin yang mampu menjadi pendorong dan memberikan pengaruh positif bagi para bawahannya dalam melakukan pekerjaannya untuk mencapai tujuan organisasi yang 
telah ditetapkan. Sehingga jika kepemimpinan pada suatu organisasi berjalan dengan baik maka akan berdampak juga terhadap kepuasan kerja karyawan.

Dan faktor lain yang dapat mempengaruhi kepuasan kerja karyawan yaitu lingkungan kerja. Menurut (Nitisemito, 2015) lingkungan kerja adalah sesuatu yang ada di sekitar para pekerja dan yang mempengaruhi dirinya dalam menjalankan tugas-tugas yang dibebankan. Lingkungan kerja yang efektif, menyenangkan dan kondusif akan mampu memberikan rasa kenyamanan sehingga dapat mempengaruhi diri karyawan dalam menjalankan tugas-tugas yang diemban. Maka dari itu lingkungan kerja harus diperhatikan dengan baik agar karyawan mendapat kepuasan dalam bekerja. Namun sebaliknya, jika lingkungan kerja tidak mendukung maka kepuasan kerja pada karyawan akan berkurang.

Penelitian ini mengambil objek penelitian pada UD.Suwarlandono art. UD. Suwarlandono art adalah perusahaan yang bergerak pada bidang industri tas yang beralamat di Jalan Utama Kedensari Nomor 40 Tanggulangin Sidoarjo, yang memiliki 150 karyawan di bagian produksi. Perusahaan ini memproduksi tas wanita dan tas travel jinjing yang di distribusikan ke Sidoarjo, Surabaya, dan Makasar. Perbedaan penelitian ini dengan penelitian yang lain yaitu adanya variabel baru seperti budaya organisasi, kepemimpinan, dan lingkungan kerja yang belum pernah di teliti oleh peneliti lain di UD. Suwarlandono art. Sehingga penelitian ini akan ada unsur kebaruan yang akan bermanfaat sebagai bahan masukan atau saran terhadap pokok permasalahan yang ada untuk menentukan kebijakan khusunya mengenai budaya organisasi, kepemimpinan, dan lingkungan kerja. Berdasarkan hasil wawancara kepada pimpinan perusahaan dan karyawan bagian produksi, peneliti memperoleh gambaran dan data bahwa terdapat kesenjangan antara standar budaya organisasi yang dibuat pimpinan perusahaan yang mendorong para karyawan untuk melakukan inovasi guna tercapainya target visi dan misi perusahaan, akan tetapi para karyawan tidak mau berinovasi, karyawan hanya mengerjakan tugas berdasarkan instruksi dari pimpinan. Pimpinan perusahaan mengharapakan karyawan bekerja dengan berorientasi pada tim, dalam menyelesaikan pekerjaanya saling membantu satu sama lain. Akan tetapi masih ada sekelompok karyawan yang tidak saling membantu. Terdapat masalah di UD. Suwarlandono art berkaitan dengan hubungan antar bawahan dan pimpinan khususnya dalam hal komunikasi pesan atau gagasan dari pimpinan kepada karyawan yang memiliki tingkat pendidikan rendah dan memiliki usia lanjut. Permasalahan dalam lingkungan kerja yaitu suhu udara di ruang kerja yang panas dikarenakan masih kurangnya alat pendingin udara di sekitar ruang kerja yang dapat menyebabkan ketidakpuasan karyawan dalam bekerja.

Kepuasan dalam kerja terbentuk dari beberapa aspek, diantaranya budaya organisasi, kepemimpinan, dan lingkungan kerja. Budaya organisasi yang melekat pada tiap anggota organisasi dapat membantu karyawan menyesuaikan diri dengan lingkungan kerja, serta membantu karyawan mengetahui tindakan yang dilakukan berdasarkan nilai-nilai yang menjadi pegangan bagi karyawan dalam menjalankan kewajiban dan perilakunya di perusahaan untuk mendapatkan hasil yang maksimal 
dan didukung oleh kepemimpinan yang baik di organisasi tersebut. Maka kepuasan kerja karyawan akan mudah tercapai. Kepuasan kerja tidak terlepas dari lingkungan kerja, karena lingkungan kerja akan mempengaruhi tiap anggota organisasi dalam menyelesaikan tugas yang diemban untuk menghasilkan kinerja yang maksimal yang akan berdampak pada variabel kepuasan kerja. Tetapi ada indikasi kepuasan kerja karyawan di UD. Suwarlandono art yang belum maksimal. Hal ini dapat dilihat dari hasil data absensi karyawan bagian produksi UD. Suwarlandono Art periode Januari 2019 sampai Oktober 2020 sebagai berikut:

Tabel 1

Data Absensi Karyawan Produksi UD.

Suwarlandono Art Periode Januari 2019-Oktober 2020

\begin{tabular}{|c|c|c|c|c|c|c|c|c|c|}
\hline \multirow[b]{2}{*}{ Bulan } & \multirow{2}{*}{$\begin{array}{c}\text { Jumlah } \\
\text { Karyawan }\end{array}$} & \multicolumn{2}{|c|}{ Sakit } & \multicolumn{2}{|c|}{ Ijin } & \multicolumn{2}{|c|}{ Alpa } & \multicolumn{2}{|c|}{ Total } \\
\hline & & $\begin{array}{l}\text { Jumlah } \\
\text { Absensi }\end{array}$ & $\%$ & $\begin{array}{l}\text { Jumlah } \\
\text { Absensi }\end{array}$ & $\%$ & $\begin{array}{l}\text { Jumlah } \\
\text { Absensi }\end{array}$ & $\%$ & $\begin{array}{l}\text { Jumlah } \\
\text { Absensi }\end{array}$ & $\%$ \\
\hline Januari & 150 & 7 & 4,67 & 4 & 2,67 & 5 & 3,34 & 16 & 10,67 \\
\hline Februari & 150 & 4 & 2,67 & 4 & 2,67 & 8 & 5,34 & 16 & 10,67 \\
\hline Maret & 150 & 5 & 3,34 & 5 & 3,34 & 4 & 2,67 & 14 & 9,34 \\
\hline April & 150 & 5 & 3,34 & 7 & 4,67 & 7 & 4,67 & 19 & 12,67 \\
\hline Mei & 150 & 7 & 4,67 & 5 & 3,34 & 4 & 2,67 & 16 & 10,67 \\
\hline Juni & 150 & 4 & 2,67 & 5 & 3,34 & 5 & 3,34 & 14 & 9,34 \\
\hline Juli & 150 & 7 & 4,67 & 8 & 5,34 & 5 & 3,34 & 20 & 13,34 \\
\hline Agustus & 150 & 5 & 3,34 & 4 & 2,67 & 4 & 2,67 & 13 & 8,67 \\
\hline September & 150 & 4 & 2,67 & 4 & 2,67 & 5 & 3,34 & 13 & 8,67 \\
\hline Oktober & 150 & 4 & 2,67 & 5 & 3,34 & 8 & 5,34 & 17 & 11,34 \\
\hline November & 150 & 5 & 3,34 & 5 & 3,34 & 4 & 2,67 & 14 & 9,34 \\
\hline Desember & 150 & 5 & 3,34 & 4 & 2,67 & 5 & 3,34 & 14 & 9,34 \\
\hline Januari & 150 & 7 & 4,67 & 5 & 3,34 & 2 & 1,34 & 14 & 9,34 \\
\hline Februari & 150 & 5 & 3,34 & 4 & 2,67 & 5 & 3,34 & 14 & 9,34 \\
\hline Maret & 150 & 5 & 3,34 & 4 & 2,67 & 4 & 2,67 & 13 & 8,67 \\
\hline April & 150 & 4 & 2,67 & 6 & 4 & 7 & 4,67 & 17 & 11,34 \\
\hline Mei & 150 & 6 & 4 & 4 & 2,67 & 4 & 2,67 & 14 & 9,34 \\
\hline Juni & 150 & 6 & 4 & 2 & 1,34 & 4 & 2,67 & 12 & 8 \\
\hline Juli & 150 & 7 & 4,67 & 4 & 2,67 & 5 & 3,34 & 16 & 10,67 \\
\hline Agustus & 150 & 5 & 3,34 & 4 & 2,67 & 4 & 2,67 & 13 & 8,67 \\
\hline September & 150 & 4 & 2,67 & 4 & 2,67 & 4 & 2,67 & 12 & 8 \\
\hline Oktober & 150 & 4 & 2,67 & 2 & 1,34 & 5 & 3,34 & 11 & 7,34 \\
\hline
\end{tabular}

Berdasarkan data absensi karyawan bagian produksi diatas menunjukkan bahwa absensi karyawan bagian produksi pada bulan Januari 2019 (10,67\%), Februari 2019 (10,67\%), Maret 2019 (9,34\%), April 2019 (12,67\%), Mei 2019 (10,67\%), Juni 2019 (9,34\%), Juli 2019 (13,34\%), Agustus 2019 (8,67\%), September 2019 (8,67\%), Oktober 2019 (11,34\%), November 2019 (9,34\%), Desember 2019 (9,34\%), Januari 2020 (9,34\%), Februari 2020 (9,34\%), Maret 2020 (8,67\%), April 2020 (11,34\%), Mei 2020 (9,34\%), Juni 2020 (8\%), Juli 2020 (10,67\%), Agustus 2020 (8,67\%), September 2020 (8\%), Oktober 2020 (7,34\%). Dari data absensi tersebut, diketahui bahwa absensi karyawan bagian produksi di UD.Suwarlandono art tidak stabil. Hal tersebut menandakan bahwa karyawan bagian produksi UD. Suwarlandono art merasakan ketidakpuasan dalam bekerja. Dari hasil pemaparan, data absensi ketidakhadiran 
karyawan bagian produksi tertinggi yaitu pada bulan Juli 2019 dengan presentase sebesar $13,34 \%$.

\section{Metode Penelitian}

Dalam penelitian ini, jenis data yang digunakan oleh peneliti menggunakan data kuantitatif. Sumber data dalam penelitian ini yaitu data primer yang dilakukan dengan pengisian kuesioner. Penelitian ini menggunakan teknik skala likert yang biasanya digunakan untuk mengukur sikap, pendapat, dan persepsi seseorang atau sekelompok orang tentang fenomena sosial dalam penelitian. Populasi pada penelitian ini adalah karyawan bagian produksi pada UD. Suwarlandono art yang berjumlah 150 orang. Menurut (Sugiyono, 2017) sampel adalah bagian dari sejumlah karakteristik yang dimiliki oleh populasi. Dalam penelitian ini menggunakan metode Probability Sampling. Dengan menggunakan kategori Proportionate Stratified Random Sampling. Sampel yang diambil pada penelitian ini adalah sebanyak 60 orang. Teknik analisis data yang digunakan dalam penelitian ini adalah partial least square atau PLS. Variabel yang dicantumkan di penelitian ini yaitu:

\section{Budaya Organisasi $\left(\mathrm{X}_{1}\right)$}

Menurut (Robbins, S. y Judge, 2014b) budaya organisasi adalah suatu sistem berbagai arti yang dilakukan oleh para anggota yang membedakan suatu organisasi dengan organisasi lainnya. Sedangkan menurut (Tanuwibowo \& Setiawan, 2015) budaya organisasi adalah seperangkat nilai-nilai, keyakinan, dan sikap yang dapat menyesuaikan serta mendorong keterlibatan karyawan yang dapat memperjelas tujuan dan arah strategi organisasi serta yang selalu menguraikan dan mengajarkan nilai-nilai dan keyakinan organisasi yang dapat membantu organisasi mencapai pertumbuhan yang lebih tinggi.

Menurut (Hasibuan, 2018) indikator budaya organisasi adalah:

1) Inovasi dan keberanian mengambil risiko

2) Perhatian terhadap detail

3) Berorientasi kepada hasil

4) Berorientasi kepada manusia

5) Berorientasi tim

6) Sikap agresif

7) Stabilitas

\section{Kepemimpinan $\left(\mathbf{X}_{2}\right)$}

Menurut (Potale \& Uhing, 2015) menyatakan kepemimpinan adalah kemampuan individu dengan menggunakan kekuasaannya melakukan proses mempengaruhi, memotivasi, dan mendukung usaha yang memungkinkan orang lain memberikan kontribusi pada pencapaian tujuan organisasi. Sedangkan (Syamsulhaq, Alwi Suddin, 2019) kepemimpinan merupakan sebagai proses untuk mempengaruhi orang lain untuk memahami dan setuju dengan apa yang perlu dilakukan dan bagaimana tugas itu dilakukan secara efektif, serta proses untuk memfasilitasi upaya individu dan kolektif untuk mencapai tujuan bersama. 
Menurut (Wibowo, 2016) indikator kepemimpinan adalah:

1) Hubungan antara bawahan dengan pemimpin

2) Struktur tugas

3) Kekuasaan

\section{Lingkungan Kerja $\left(\mathbf{X}_{3}\right)$}

Menurut (Nitisemito, 2015) lingkungan kerja adalah sesuatu yang ada disekitar para pekerja dan yang mempengaruhi dirinya dalam menjalankan tugas-tugas yang dibebankan. Sedangkan menurut (Nabawi, 2019) lingkungan kerja merupakan keseluruhan alat perkakas dan bahan yang dihadapi, lingkungan sekitarnya.

Dimana seseorang bekerja, metode kerjanya, serta pengaturan kerjanya baik sebagai perseorangan maupun sebagai kelompok.

Indikator lingkungan kerja menurut (Rahmawati, 2014) adalah:

1) Kebersihan ruangan

2) Suhu udara

3) Ruang gerak

4) Penerangan

5) Pewarnaan

\section{Kepuasan Kerja (Y)}

Menurut (Handoko, 2001) kepuasan kerja merupakan keadaan emosional yang menyenangkan atau tidak menyenangkan dengan para karyawan memandang pekerjaan mereka.

Indikator dari kepuasan kerja menurut (Wibowo, 2016):

1) The work itsefl (pekerjaan itu sendiri)

2) Quality of supervision (kualitas pengawasan)

3) Relationship with co-workers (hubungan dengan rekan kerja)

4) Pay (bayaran)

\section{Hasil dan Pembahasan}

\section{Analisa Outer Model}

\section{a. Uji Validitas}

Suatu indikator dinyatakan valid jika mempunyai outler loading di atas 0,5 terhadap konstruk yang dituju. Output SmartPLS untuk Outer Loading pada hasil penelitian dapat disajikan dalam bentuk gambar sebagai berikut:

Syntax Idea, Vo

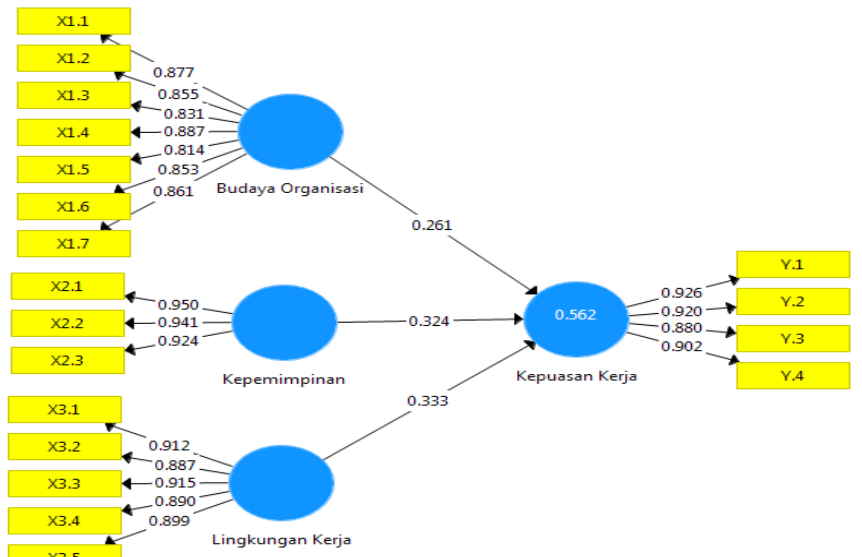




\section{Gambar 1}

\section{Pengujian Validitas Data}

Pada gambar 1 diatas menunjukkan bahwa nilai outler loading pada setiap item $>$ r tabel yaitu 0,2542 dan nilai sig <0,05. Hal ini dapat dinyatakan bahwa seluruh item penyataan pada kuisioner valid dan telah memenuhi convergent validity.

\section{b. Uji Reliabilitas}

Uji reliabilitas dilakukan dengan melihat nilai composite reliability dari blok indikator yang mengukur konstruk. Hasil composite reliability akan menunjukkan nilai yang memuaskan jika di atas 0,7 dan nilai cronbach alpha $>0,6$. Berikut adalah nilai composite \& cronbach alpha reliability pada output:

Tabel 2

Composite \& Cronbach's Alpha Reliability

\begin{tabular}{|c|c|c|}
\hline & Cronbach's Alpha & $\begin{array}{l}\text { Composite } \\
\text { Reliability }\end{array}$ \\
\hline Budaya Organisasi & 0.938 & 0.950 \\
\hline Kepemimpinan & 0.933 & 0.957 \\
\hline Kepuasan Kerja & 0.928 & 0.949 \\
\hline Lingkungan Kerja & 0.942 & 0.956 \\
\hline
\end{tabular}

Tabel 2 diatas menunjukkan bahwa nilai composite reliability untuk semua konstruk adalah > 0,7 dan nilai Cronbach's Alpha untuk semua kontruk berada di atas 0,6. Hal ini menunjukkan bahwa semua konstruk pada model yang diestimasi memenuhi kriteria discriminant validity.

\section{Analisa Inner Model}

Berdasarkan pengolahan data yang telah dilakukan dengan menggunakan program smartPLS 3.0, diperoleh nilai R-Square sebagai berikut:

Tabel 3

Nilai $R$-Square

\begin{tabular}{|c|c|c|}
\hline & R Square & $\begin{array}{l}\text { R Square } \\
\text { Adjusted }\end{array}$ \\
\hline Kepuasan Kerja & 0.562 & 0.538 \\
\hline
\end{tabular}


Berdasarkan pada tabel 3 di atas, dapat diketahui bahwa nilai R-Square pada pengaruh budaya organisasi, kepemimpinan dan lingkungan kerja terhadap kepuasan kerja sebesar 0.562, artinya variabel budaya organisasi, kepemimpinan dan lingkungan kerja mampu mempengaruhi variabel kepuasan kerja sebesar 56,2\%, sedangkan sisanya 43,8\% dijelaskan oleh variabel lain diluar variabel yang diteliti.

\section{a. Pengujian Hipotesis}

\section{1) Pengujian terhadap hipotesis 1}

Pengujian hipotesis 1 yang berbunyi "Budaya organisasi berpengaruh positif terhadap kepuasan kerja karyawan UD. Suwarlandono Art". Uji hipotesis pada penelitian ini dilakukan dengan melihat nilai T-Statistics. Hipotesis penelitian dapat dinyatakan diterima apabila nilai $t_{\text {hitung }}>t_{\text {tabel }}$. Berikut ini adalah hasil uji hipotesis yang diperoleh dalam penelitian ini melalui inner model:

Tabel 4

Pengujian Hipotesis

\begin{tabular}{lcccc}
\hline & $\begin{array}{c}\text { Original } \\
\text { Sample } \\
(\mathbf{O})\end{array}$ & $\begin{array}{c}\text { Sample } \\
\text { Mean } \\
(\mathbf{M})\end{array}$ & $\begin{array}{c}\text { Standard } \\
\text { Deviation } \\
\text { (STDEV) }\end{array}$ & $\begin{array}{c}\text { T Statistics } \\
(\mid \mathbf{O} / \text { STDEV|) }\end{array}$ \\
\hline $\begin{array}{l}\text { Budaya Organisasi -> } \\
\text { Kepuasan Kerja }\end{array}$ & 0.261 & 0.279 & 0.095 & 2.741 \\
\hline $\begin{array}{l}\text { Kepemimpinan -> Kepuasan } \\
\text { Kerja }\end{array}$ & 0.324 & 0.311 & 0.12 & 2.695 \\
\hline $\begin{array}{l}\text { Lingkungan Kerja -> } \\
\text { Kepuasan Kerja }\end{array}$ & 0.333 & 0.33 & 0.135 & 2.474 \\
\hline
\end{tabular}

Sumber: Lampiran Output SmartPLS, data diolah

Berdasarkan tabel 4 diperoleh nilai $t_{\text {hitung }}$ 2,741 dimana nilai $t_{\text {tabel }}$ sebesar 1,671. Sehingga nilai $t_{\text {hitung }}>t_{\text {tabel }}$ yaitu $2,741>1,671$ dengan demikian maka dapat dinyatakan bahwa variabel budaya organisasi berpengaruh positif dan signifikan terhadap kepuasan kerja.

\section{2) Pengujian terhadap hipotesis 2}

Pengujian hipotesis 2 yang berbunyi "Kepemimpinan berpengaruh positif terhadap kepuasan kerja karyawan UD. Suwarlandono Art”. Uji hipotesis pada penelitian ini dilakukan dengan melihat nilai T-Statistics. Hipotesis penelitian dapat dinyatakan diterima apabila nilai $t_{\text {hitung }}>t_{\text {tabel }}$.

Berdasarkan tabel 4 diperoleh nilai thitung 2,695 dimana nilai tabel sebesar 1,671. Sehingga nilai $t_{\text {hitung }}>t_{\text {tabel }}$ yaitu 2,695 $>1,671$ dengan demikian maka dapat dinyatakan bahwa variabel kepemimpinan berpengaruh positif dan signifikan terhadap kepuasan kerja.

\section{3) Pengujian terhadap hipotesis 3}

Pengujian hipotesis 3 yang berbunyi "Lingkungan kerja berpengaruh positif terhadap kepuasan kerja karyawan UD. Suwarlandono Art”. Uji 
hipotesis pada penelitian ini dilakukan dengan melihat nilai T-Statistics. Hipotesis penelitian dapat dinyatakan diterima apabila nilai $t_{h i t u n g}>t_{\text {tabel }}$.

Berdasarkan tabel 4 diperoleh nilai thitung 2,474. Dimana nilai tabel sebesar 1,671. Sehingga nilai $t_{\text {hitung }}>t_{\text {tabel }}$ yaitu 2,474 $>1,671$ dengan demikian maka dapat dinyatakan bahwa variabel lingkungan kerja berpengaruh positif dan signifikan terhadap kepuasan kerja.

\section{4) Pengaruh variabel budaya organisasi terhadap kepuasan kerja}

Berdasarkan dari pengujian hipotesis yang dilakukan dengan menggunakan uji-t diperoleh hasil yang menyatakan hipotesis diterima, yang artinya variabel budaya organisasi berpengaruh signifikan terhadap kepuasan kerja Karyawan yang telah memahami budaya organisasi dengan baik akan memberikan kepuasan tersendiri bagi karyawan dalam bekerja. Jika semakin banyak aspek-aspek yang terdapat pada diri karyawan yang sesuai dengan budaya organisasi tempatnya bekerja, maka akan semakin tinggi pula kepuasan kerjanya.

Hasil penelitian ini sejalan dengan pendapat Menurut (Nimran, 2016) semakin kuat budaya organisasi dalam perusahaan maka kepuasan kerja karyawan akan semakin meningkat. Karyawan merasa perusahaan selalu menekankan untuk selalu cermat dan memperhatikan secara detail saat melakukan pekerjaan.

Penelitian diatas sejalan dengan penelitian terdahulu yang pernah dilakukan oleh (Fajriyanti, Panjaitan, \& Kuswanto, 2019) dimana hasil penelitian menunjukkan bahwa budaya organisasi memiliki pengaruh positif dan signifikan terhadap kepuasan kerja.

\section{5) Pengaruh variabel kepemimpinan terhadap kepuasan kerja}

Berdasarkan dari pengujian hipotesis yang dilakukan dengan menggunakan uji-t diperoleh hasil yang menyatakan hipotesis diterima, yang artinya kepemimpinan berpengaruh positif dan signifikan terhadap kepuasan kerja. Pemimpin yang sukses adalah pemimpin yang mampu menjadi pencipta dan pendorong bagi bawahannya dengan menciptakan suasana dan budaya kerja yang dapat memacu pertumbuhan dan perkembangan kinerja karyawannya yang akan berdampak pada kepuasan kerja karyawan.

Hasil penelitian ini sejalan dengan pendapat Menurut (Potale \& Uhing, 2015) mendefinisikan kepemimpinan merupakan kemampuan individu dengan menggunakan kekuasaannya melakukan proses mempengaruhi, memotivasi, dan mendukung usaha yang memungkinkan orang lain memberikan kontribusi pada pencapaian tujuan organisasi. Sedangkan menurut (Yukl, 2005) kepemimpinan merupakan salah satu faktor penting yang dapat mempengaruhi kepuasan kerja. Perilaku dari seorang pemimpin dapat mempengaruhi kepuasan dan kinerja dari bawahan. 
Penelitian diatas sejalan dengan penelitian terdahulu yang pernah dilakukan oleh (Shintiya \& Hamdani, 2020) Dimana hasil penelitian menunjukkan bahwa semakin baik kepemimpinan yang diterapkan maka semakin tinggi tingkat kepuasan kerja yang diperoleh karyawan.

\section{6) Pengaruh variabel lingkungan kerja terhadap kepuasan kerja}

Berdasarkan dari pengujian hipotesis yang dilakukan dengan menggunakan uji-t di peroleh hasil yang menyatakan hipotesis diterima, yang artinya lingkungan kerja berpengaruh signifikan terhadap kepuasan kerja. Lingkungan kerja yang dapat memberikan rasa nyaman dan aman kepada karyawan akan menumbuhkan rasa semangat dalam melakukan pekerjaaan. Kondisi nyaman yang dirasakan karyawan dalam bekerja akan menimbulkan mood positif dalam bekerja, kondisi ini akan berdampak positif terhadap meningkatnya kepuasan karyawan dalam bekerja.

Hasil penelitian ini sejalan dengan pendapat Menurut (Nitisemito, 2015) menyatakan bahwa lingkungan kerja merupakan semua hal atau segala sesuatu yang berada dalam lingkungan pekerja yang dapat mempengaruhi diri dalam menjalankan pekerjaan. Lingkungan kerja yang baik dan kondusif sangat dibutuhkan karyawan demi tercapainya kepuasan kerja karyawan, sehingga target-target perusahaan yang dibebankan bisa segera terwujud.

Hasil penelitian ini sejalan dengan penelitian terdahulu yang pernah dilakukan oleh (Ardianti, Qomariah, \& Wibowo, 2018) yang menujukkan bahwa semakin baik lingkungan kerja karyawan maka semakin baik pula kepuasan kerja karyawan.

\section{Kesimpulan}

Tujuan penelitian ini adalah untuk mengetahui pengaruh Budaya Organisasi, Kepemimpinan, dan Lingkungan Kerja terhadap Kepuasan Kerja Karyawan pada UD. Suwarlandono Art di Tanggulangin. Berdasarkan hasil analisa dan pembahasan dapat disimpulkan sebagai berikut: Pertama, Budaya organisasi dapat memberikan konstribusi terhadap kepuasan kerja. Semakin baik budaya organisasi maka akan semakin tinggi kepuasan kerja tersebut. Kedua, Kepemimpinan dapat memberikan konstribusi terhadap kepuasan kerja. Semakin baik kepemimpinan maka akan semakin tinggi kepuasan kerja tersebut. Ketiga Lingkungan kerja dapat memberikan konstribusi terhadap kepuasan kerja. Semakin baik lingkungan kerja maka akan sema kin tinggi kepuasan kerja tersebut.

\section{BIBLIOGRAFI}

Ardianti, F. E., Qomariah, N., \& Wibowo, Y. G. (2018). Pengaruh motivasi kerja, kompensasi dan lingkungan kerja terhadap kepuasan kerja karyawan (Studi kasus pada PT. Sumber Alam Santoso Pratama Karangsari Banyuwangi). Jurnal Sains Manajemen Dan Bisnis Indonesia, 8(1).Google Scholar

Fajriyanti, F., Panjaitan, N. K., \& Kuswanto, S. (2019). Pengaruh Budaya Organisasi 
dan Kohesivitas Kelompok Terhadap Kepuasan Kerja Karyawan di PT Bank BNI Syariah. Jurnal Aplikasi Bisnis Dan Manajemen (JABM), 5(3), 465. Google Scholar

Handoko, T. H. (2001). Manajemen Personalia dan Sumber Daya Manusia Edisi 2. Yogyakarta: BPFE.

Handoko, T. H. (2016). Manajemen personalia dan sumberdaya manusia. Yogyakarta: BPFE. Google Scholar

Hasibuan, M. S. (2018). Manajemen Sumber Daya Manusia. Melayu. In Manajemen Sumber Daya Manusia.

Nabawi, R. (2019). Pengaruh Lingkungan Kerja, Kepuasan Kerja dan Beban Kerja Terhadap Kinerja Pegawai. Maneggio: Jurnal Ilmiah Magister Manajemen, 2(2), 170-183. Google Scholar

Nimran, U. (2016). Perilaku Organisasi. Jakarta: Kencana.

Nitisemito, A. S. (2015). Manajemen Personalia, Cetakan kedelapan. Jakarta: Ghalia Indonesia. Google Scholar

Potale, R., \& Uhing, Y. (2015). Pengaruh kompensasi dan stres kerja terhadap kepuasan kerja karyawan Pada PT. Bank Sulut Cabang Utama Manado. Jurnal EMBA: Jurnal Riset Ekonomi, Manajemen, Bisnis Dan Akuntansi, 3(1). Google Scholar

Rahmawati, N. (2014). Analisis Pengaruh Lingkungan Kerja dan Motivasi Terhadap Kinerja Karyawan di PKU Aisyiyah Boyolali. Universitas Muhammadiyah Surakarta. Google Scholar

Robbins, S. y Judge, T. (2014a). Políticas y prácticas de recursos humanos. In Comportamiento organizacional.

Robbins, S. y Judge, T. (2014b). Políticas y prácticas de recursos humanos. In Comportamiento organizacional.

Shintiya, C. A. D., \& Hamdani, M. (2020). Pengaruh Kepemimpinan Dan Motivasi Terhadap Kepuasan Kerja Pegawai Pada Pd. Bpr Bkk Blora. ECONBANK: Journal of Economics and Banking, 2(2), 129-137. Google Scholar

Sugiyono. (2017). MetodePenelitian Kuantitatif, Kualitatif dan R\&D. Bandung: PT Alfabet. Sugiyono. (2017). MetodePenelitian Kuantitatif, Kualitatif Dan R\&D. Bandung: PT Alfabet. Google Scholar

Syamsulhaq, Alwi Suddin, dan E. W. (2019). Pengaruh Kompensasi, Kepemimpinan, Dan Komitmen Organisasi Terhadap Kepuasan Kerja Pegawai (Survei pada Pegawai Dinas Perhubungan Kabupaten Sragen). Jurnal Sumber Daya Manusia, 3(2), 827-838. 
Pengaruh Budaya Organisasi Kepemimpinan, dan Lingkungan Kerja terhadap Kepuasan Kerja Karyawan

Tanuwibowo, M. H., \& Setiawan, R. (2015). Pengaruh Budaya Organisasi Dan Motivasi Kerja Terhadap Kinerja Karyawan Pada PT Lestari Purnama Perkasa. Jurnal Agora, 3(2), 60-69. Google Scholar

Wibowo. (2016). Perilaku Dalam Organisasi (Rajawali Pers., Ed.). Jakarta.

Yukl, G. (2005). Kepemimpinan dalam organisasi. Manado. Google Scholar

Copyright holder :

Ayu.Faiza Rochmah, Bowo Santoso,.Endang Iriyanti (2021)

First publication right :

Jurnal Syntax Idea

This article is licensed under:

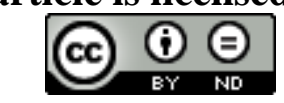

